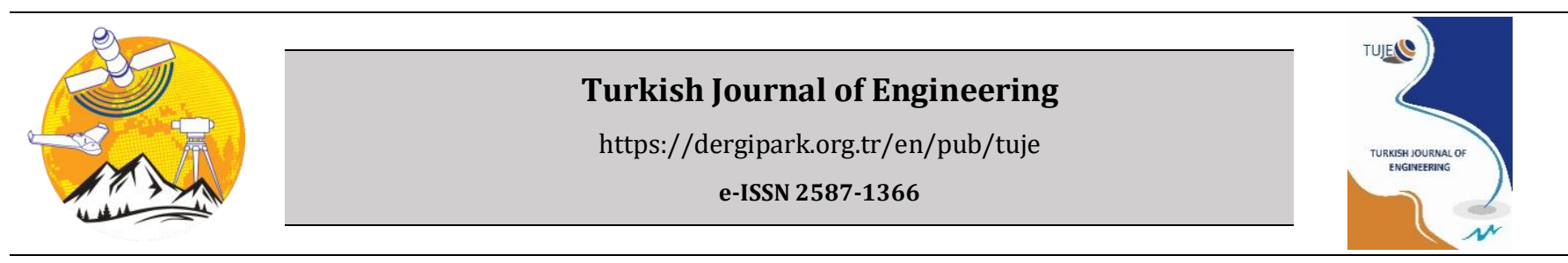

\title{
A low-cost smart home automation for elderly who has Alzheimer's or age-related memory loss
}

\author{
Ayse Nur Ay*1 ${ }^{*}$, Baris Cokacar ${ }^{1}$, Ibrahim Turkmen ${ }^{1} \mathbb{C}$ \\ ${ }^{1}$ Sakarya University of Applied Sciences, Mechatronics Engineering Department, Sakarya, Turkey.
}

Keywords

Smart home

Automation

LabVIEW

Arduino

\begin{abstract}
Technology, which is developing considerable in recent years, have influence on automation systems as well. With the advancement of the technology, people want to remote access systems and artificial intelligent systems that can consider for them. Nowadays, people started to tend smart house systems in order to facilitate their lives and to live more peaceful. In this study, a smart house automation system was designed on LabVIEW platform for people who has age-related memory loss or Alzheimer's or who cannot fulfill their needs. The house performs some functions namely, medication reminder, pulse-control sensor, temperature control and fire alarm, door/window warning system, burglar alarm, and lighting systems. This study is based on, communication via e-mail. If there is any abnormality in the house, the system allows users to have an e-mail about the current situation. Since, the study targets elderly or people who needs medical care, this low-cost design can be very preferable in the future.
\end{abstract}

\section{INTRODUCTION}

In 1980, "Smart house" was used as a new concept for the first time. This detail was regarded as historical development of smart houses. In 1984, the first smart house was made in Turkey. The main idea behind this house was just to give a comfortable life style to ordinary people. However later on, many commercial options controlled by individuals were presented.

The house automation systems were continued to be improved in 90's as well. In 1993, Christos Douligeris presented the intelligent home systems. These systems enabled the user to communicate with the system via voice or visual communications. He also divided the house automation products into three categories: interactive smart products, intelligent subsystems, and central home automation systems (Douligeris, 1993).

In 1995, Baki Koyuncu suggested home automation system using phone wires and a PC (Koyuncu, 1995).

In 1998, remote control system carried out by Coskun and Ardam which was considered as a milestone for smart house technologies. Their system included a phone-based remote controller which can detect the user number in order to prevent unknown users for control unit (Coskun \& Ardam, 1998).

With the developed technology, the home automation systems began to be more affordable option for people in early 2000s.

Aldrich defined a smart home as the house which is equipped with computing and information technologies and enable security and entertainment to the users via control systems (Aldrich, 2003). The smart houses have been defined as the house which facilitates many technological features that make people life easier. Nowadays, in many studies, different terms were used instead of "smart house" such as smart construction, construction automation system, integrated house and smart building systems. Based on these terms, a smart house can be defined as the house which increases life standards of residents through computer and communication technologies (Mennicken et al. 2014).

Many studies direct their focus on designing smart home automation systems using microcontrollers (Bhardwaj et al. 2015). Soliman et al. designed a real- 
time automation system using arduino and LabVIEW. Their system included temperature management, light energy saving and security camera (Soliman et al. 2017). Zaro et al., 2021 confirmed and extended previous arduino based studies by implementing $\mathrm{Wi}-\mathrm{Fi}$ connection to the system which enabled users to access to control and monitor the system from anywhere in the house. Even though these developments were remarkable for home automation systems, in case of elderly users who needs medical care, the functions of the systems must be advanced.

With the increase of elderly population in all around the world, a lot of research direct their focus to provide a smart home that can lead them to a better life quality (Pal et al. 2017). With the priority of these people security, the smart systems have been continued to be developed. Particularly, with the necessity of healthmonitoring and independent assisted living, smart houses became more preferable for elderly or people who need healthcare especially who have Alzheimer or age-related memory lost. As known, Alzheimer is the most common form of dementia and caring people with Alzheimer is a very challenging task for their family members. Brunete et al. presented that smart-homes can help with Alzheimer's in daily tasks fields and security (Brunete González, et al. 2017). Technological solutions and intelligent assistive technologies for elderly with Alzheimer's were continued to be developed (Ienca et al. 2017; Maresova et al. 2018). Since people with Alzheimer's or who has age-related memory loss may live alone in the house, remote monitoring technologies became more important for automation systems (Muurling et al. 2021).

In this study, a smart house system which targeted especially people who have Alzheimer or age-related memory loss was designed using Arduino microcontroller and LabVIEW platform. According to their needs, different functions have been applied to the system.

\section{MATERIALS AND METHOD}

In this study, LabVIEW, Arduino UNO R3, Arduino 2 Channel Relay Module, DC6 12V Mini Water Pump, LM335-Z Temperature Sensor, Pulse-Heart Rhythm Sensor, Arduino Motion Sensor, Leds, Fan and $12 \mathrm{~V}$ adaptor have been operated. The block diagram of the study is given in Figure 1.

Firstly, these six functions that utilized the automation in the house were set and the circuits were designed on LabVIEW step by step. These functions are namely, medication reminder, pulse-control sensor, temperature control, fire alarm, door/window warning system, burglar alarm, and lighting systems.

All inputs and outputs were available through Arduino communication. Serial communication was used as a communication technique between LabVIEW and arduino. Makerhub serial communication software, which is an add-on of LabVIEW, was downloaded via NI VISA. In this add-on, the arduino, which is connected to the computer with the Com port, was introduced to the LabVIEW. Afterwards, the sensors were connected to the arduino and the data was read through analog and digital data reading methods via LabVIEW.

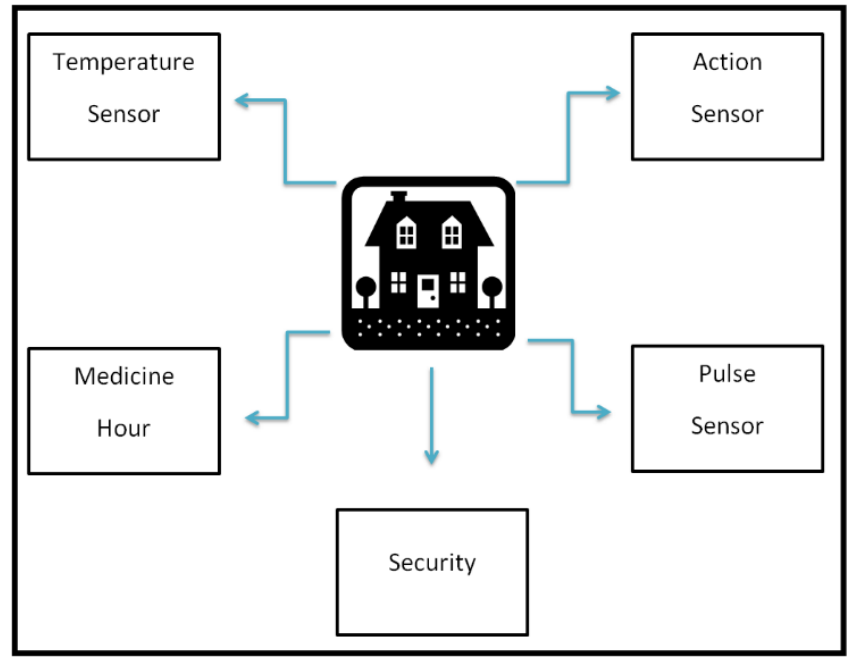

Figure 1. The block diagram of the study.

Digital filters were used for prepocessing of the signals. For example, for the pulse sensor, a band-pass and a band-stop filter were used. The band-pass filter was used to get signals in a certain frequency range in which ECGs can be recognised easily $(0,1-120 \mathrm{~Hz}$ ) (Ay et al. 2017).

The band-stop filter, which reduces frequencies in a certain range to very low levels, was used to eliminate $50 \mathrm{~Hz}$ powerline interference.

\subsection{Medication Reminder}

A medication reminder is one of the most important functions of this study. This application was designed in order to remind a person his/her medical requirements. This option is very useful especially elder people who is suffering from age-related memory loss or Alzheimer.

Working principle of the application was designed over LabVIEW and communication between the app and the user is provided through Wi-Fi and e-mail. Figure 2 represents the LabVIEW block diagram of the medication reminder application.

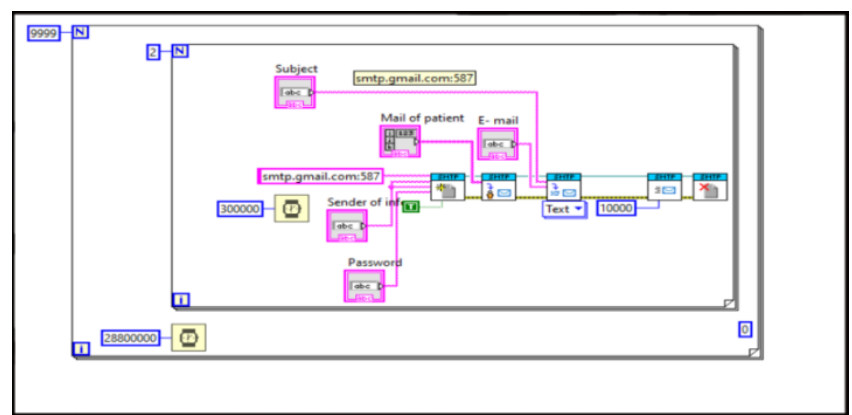

Figure 2. LabVIEW block diagram of the medication reminder.

The front panel of LabVIEW which enables the reminder algorithm to be compiled which can be seen in Figure 3. 


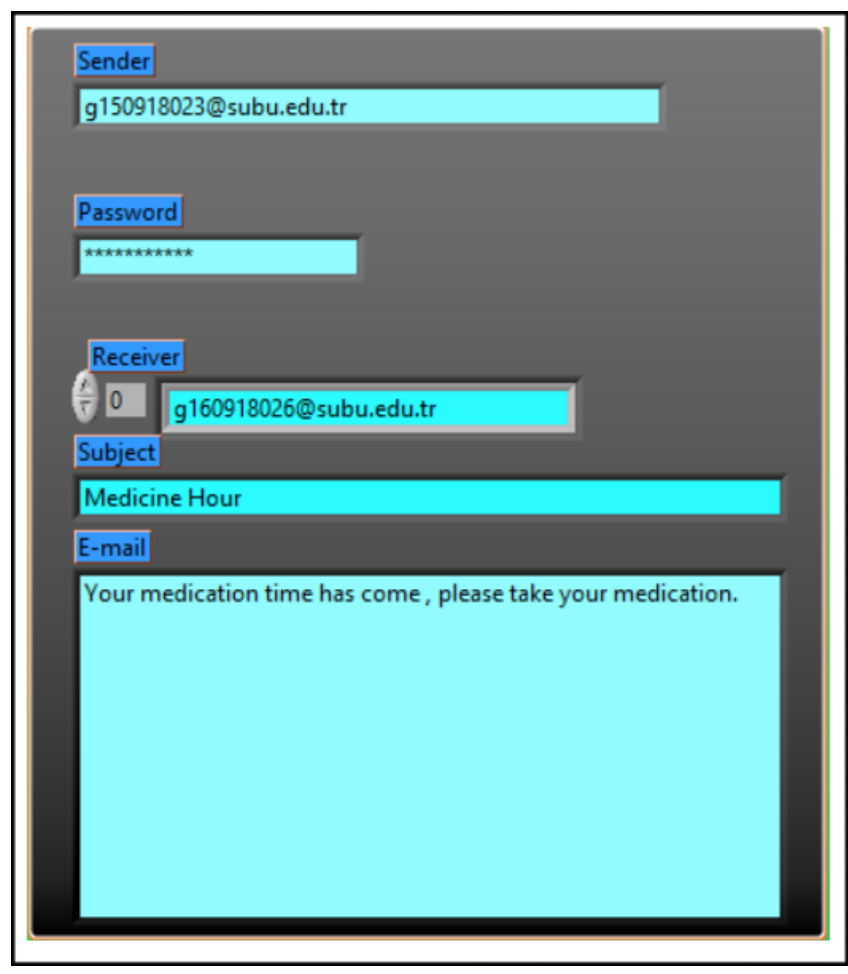

Figure 3. The front panel of LabVIEW for medication reminder.

\subsection{Pulse Control Sensor}

The pulse rate sensor that was used for this study can be connected to Arduino. This sensor, measures the pulse by fixing it to fingertip. Thanks to the noise canceling circuit on it, a stable measurement can be taken. Supply voltage of this sensor was 3-5 Volts. When the user puts his/her finger on the pulse rate sensor, the values detected from the sensor can be recorded with analog data reading method through arduino via LabVIEW.

In this application, the object was that pulse rate of an individual was taken instantaneously so health problems of a patient could easily be diagnosed and solved under doctor control. In order to diagnose and solve these problems, the application saved instant pulse rates on a .txt file and made an emergency call to units if pulse rate of a patient was at critical level. A sample txt. file is displayed in the figure below.

PULSE : 74,560547
PULSE : 75,546875
PULSE : 75,146484
PULSE : 73,896484
PULSE : 76,240234
PULSE : 78,583984
PULSE : 76,464844
PULSE : 72,509766
PULSE : 74,414062
PULSE : 75,292969
PULSE : 75,146484

Figure 4. A sample txt. file for recording pulse rates.
The application was written on LabVIEW and was imported as analog data from Arduino Pulse heart Rhythm sensor. Communication was provided through Wi-Fi via an e-mail.

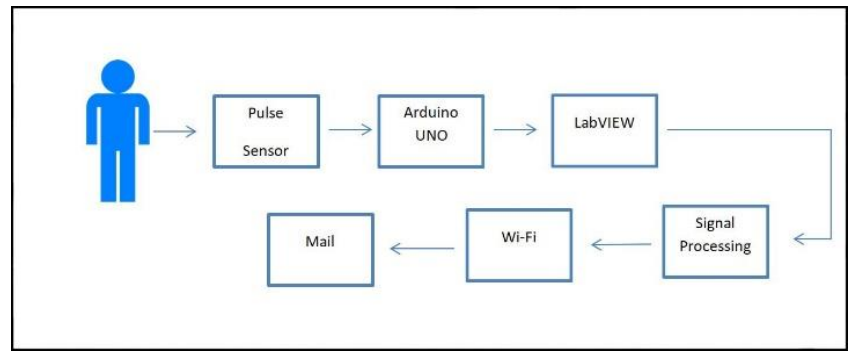

Figure 5. The block diagram of the pulse sensor usage

The block diagram of the heart rate calculation in LabVIEW is presented in Figure 6.

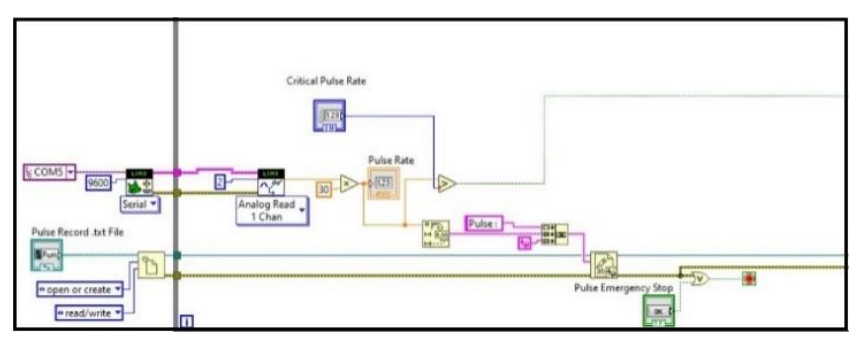

Figure 6. Block diagram of heart rate calculation.

The program was designed as user friendly. A critical pulse rate was added to the panel. Therefore, the value can be adjusted according to user's age or medical condition. Figure 7 represents the front panel of heart rate calculation program.

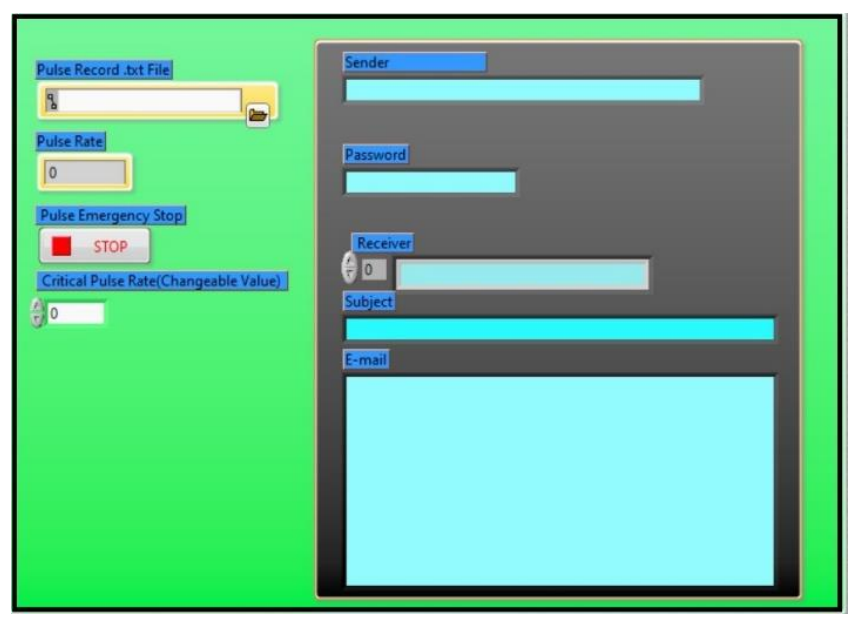

Figure 7. Front panel of heart rate calculation program on LabVIEW.

\subsection{Temperature Sensor and Fire Alarm}

This application was designed in order to control temperature of a home and provide life safety. Working principal of the application was that necessary parts of automation turns on according to temperature rates which was taken from thermocouple through analog. For instance, when temperature is below $25^{\circ} \mathrm{C}$, it is stated that environment is cold, when temperature is $26^{\circ} \mathrm{C}-33^{\circ} \mathrm{C}$, it is also stated that temperature of environment is normal. Between $33^{\circ} \mathrm{C}$ and $40^{\circ} \mathrm{C}$ Temperature value range it is stated that environment is 
hot and fan turns on by means of digital data reading. When temperature is above $40^{\circ} \mathrm{C}$, the fire alarm starts and gives emergency call to require units via $\mathrm{Wi}-\mathrm{Fi}$ and fire extinguish system turns on by means of digital data reading. In order to adjust the limit temperature degree, a critical value option was added to the panel.

The block diagram of working principle of the temperature sensor is displayed in Figure 8.

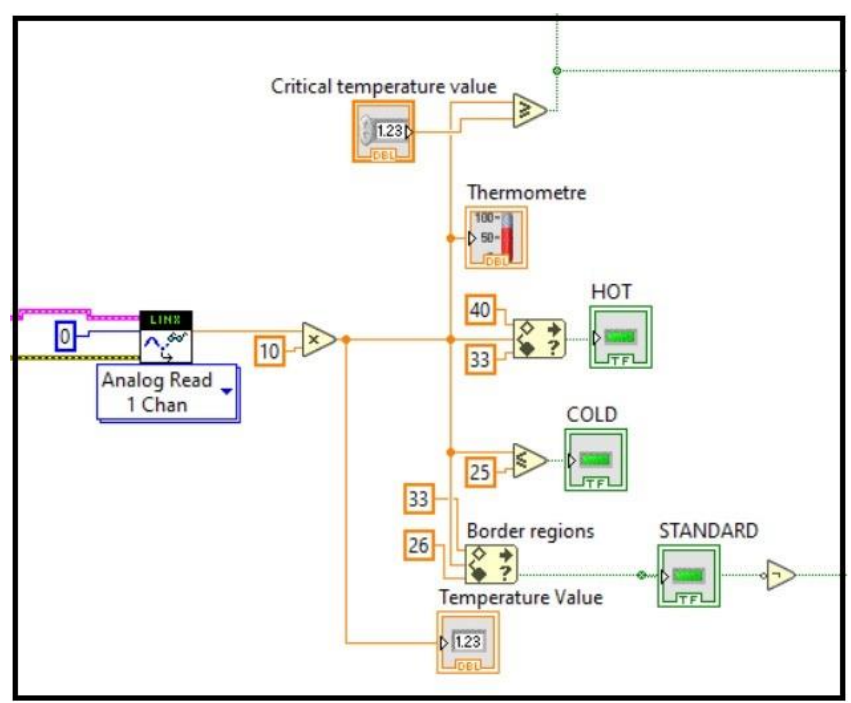

Figure 8. The block diagram of working principle of temperature sensor.

LM335 Temperature Sensor Integration can measure the temperature of the environment thanks to the temperature sensor circuit in it. This Temperature Sensor gives output between 2.95V - 3.01V. Reverse current is $15 \mathrm{~mA}$ forward current is $10 \mathrm{~mA}$. It can measure between $-40{ }^{\circ} \mathrm{C}$ and $100{ }^{\circ} \mathrm{C}$ temperatures. The front panel of temperature sensor is shown in Figure 9.

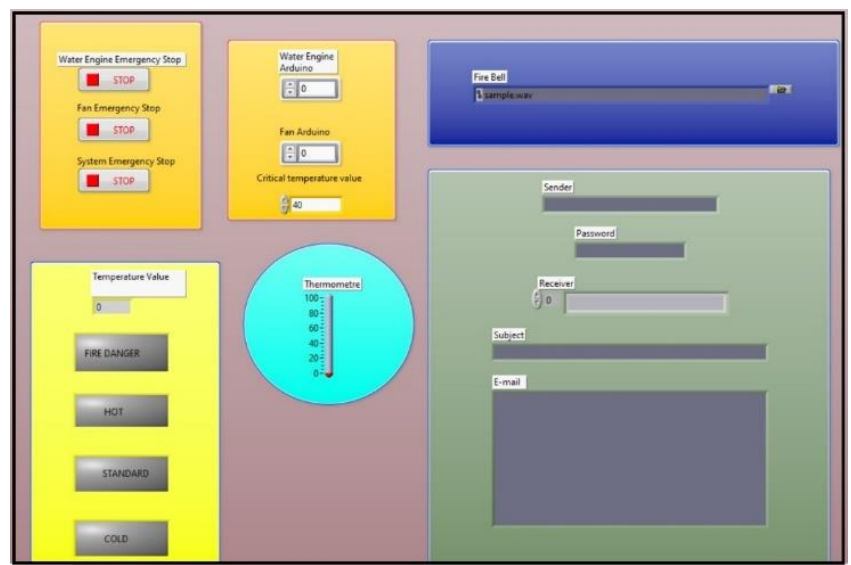

Figure 9. The front panel of the temperature sensor

According to this program, when the temperature value shows over $33^{\circ} \mathrm{C}$, communication from Arduino is provided, the inverted relay is activated and operates the fan to cool the house. The block diagram of fan control is displayed in Figure 10.

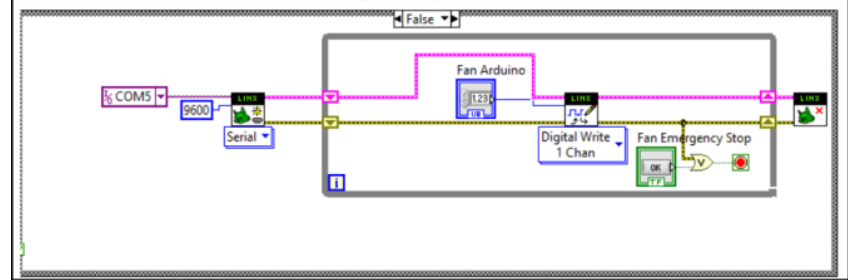

Figure 10. The block diagram of the fan control.

\subsection{Door Window Warning System}

This application was designed in order to provide safety cautions of a person and the application sends email via Wi-Fi in order that the person close the door and the windows. The algorithm behind this function has the same working principle with the medication reminder function.

\subsection{Burglar Alarm}

This application was designed in order to take precaution towards the hazards which comes from outside. Working principal is shown on LabVIEW by being imported 1 / 0 data from motion sensor via data reading. Burglar alarm turns on and gives an emergency call to required units when it perceive an activity. The block diagram of the burglar alarm system is displayed in Figure 11.

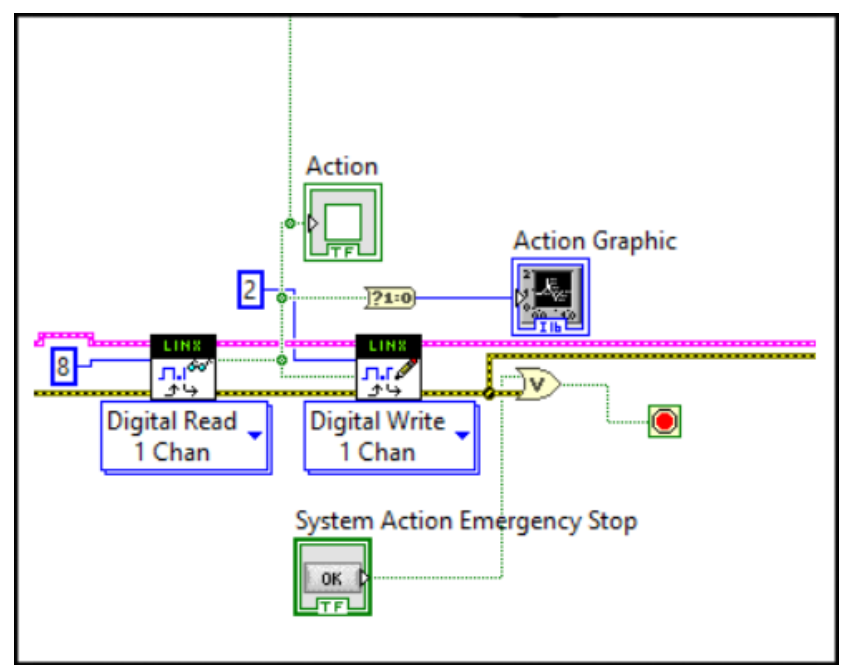

Figure 11. Burglar alarm block diagram

According to the burglar alarm algorithm, when the motion sensor detects a motion, it can be seen on the front panel of the program with the help of the green light. When the signal is received, the alarm sound starts with the help of LabVIEW. The front panel of burglar alarm algorithm is shown in Figure 12.

The algorithm behind burglar alarm function has the same working principle with the temperature control function. 


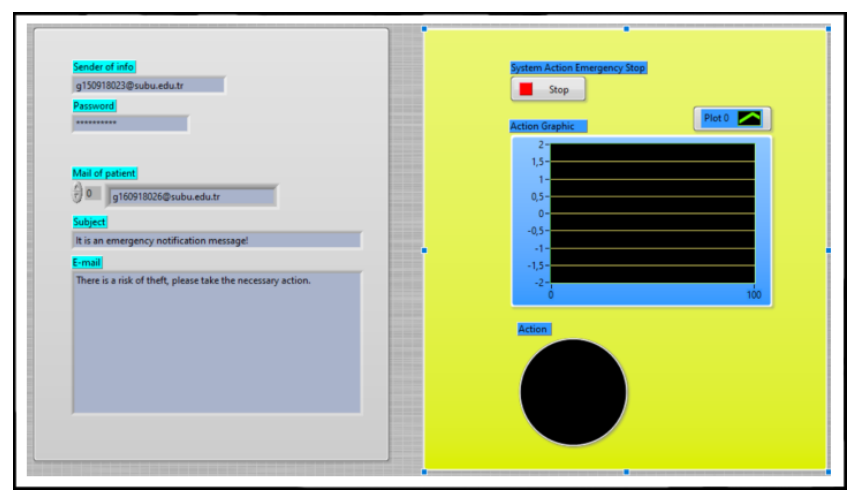

Figure 12. Burglar alarm front panel

\subsection{Lighting System}

3 led light were set up in order to enlighten the smart house. It was connected through Arduino and 1 and 0 control was made over LabVIEW. The logic behind lighting system is simply displayed in figure 13 .

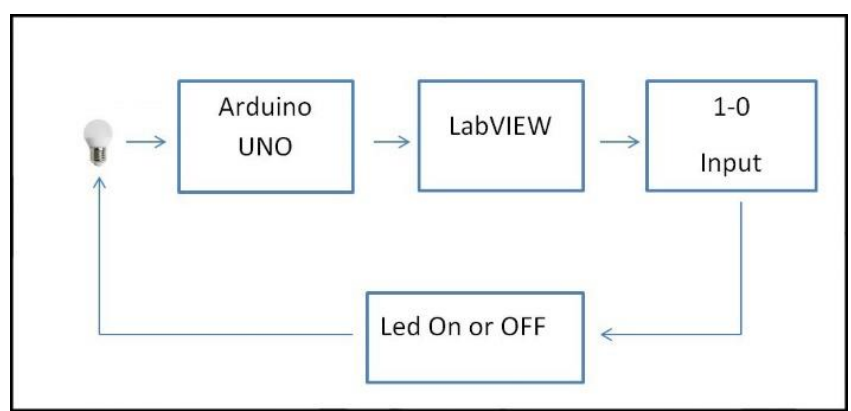

Figure 13. Block diagram of lighting system

Figure 14 and 15 represents the algorithm and user interface of the lighting system.

In this designed smart house, more comfortable life was tried to be provided to elderly especially who has age-related memory loss or Alzheimer's. Besides, the system keeps the security forefront.

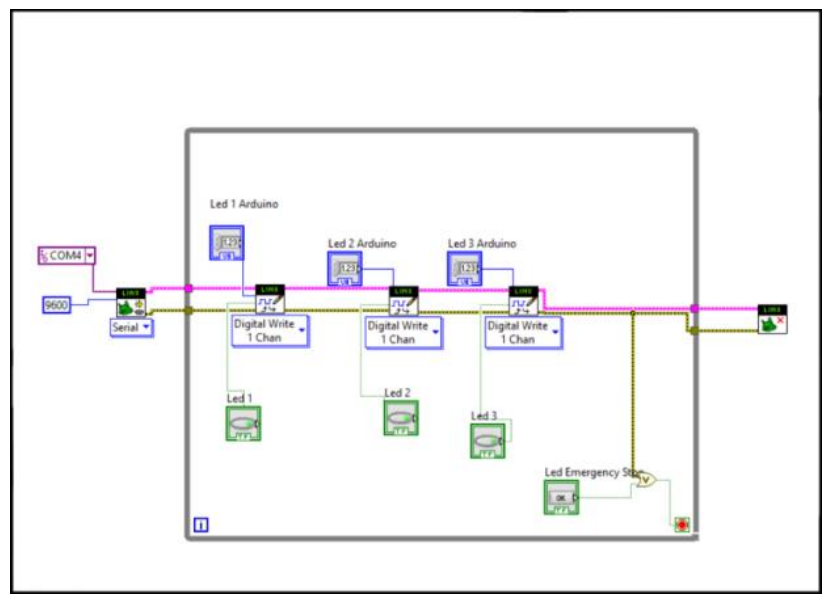

Figure 14. LabVIEW Block diagram of lighting rear panel

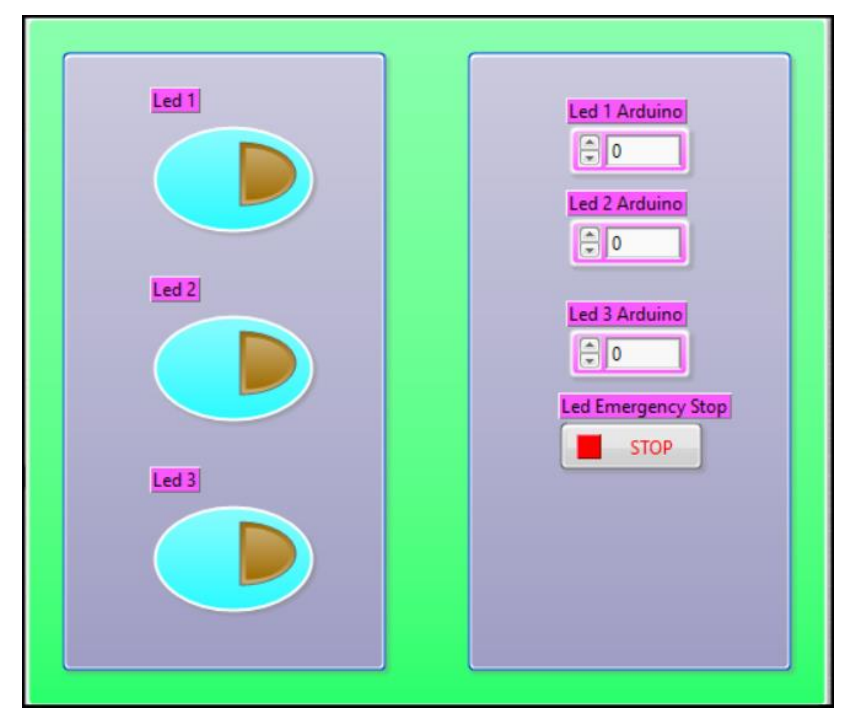

Figure 15. The front panel of lighting system.

\section{RESULTS AND DISCUSSION}

In this study, smart house automation design in LabVIEW platform was carried out in order to increase life standards of elderly or healthcare needed people and facilitate lives of people who needs assistance. For that purpose, six different functions were applied to the automation system. As it was detailed in the materials and methods sections, all functions were compiled successfully on LabVIEW.

The performance criteria and limitations of this study are taken as reference according to the values of a healthy and young person. However, these values can be easily changed by user from the block diagram of the LabVIEW program. For example, ideal temperature level can be optimized by a user. Therefore, the results of the simulations were determined according to user preferences.

A sample e-mail result that is set for reminding medication hour is displayed in Figure 16.

\begin{tabular}{|c|}
\hline \multicolumn{2}{|c|}{ Medicine hour } \\
IBRAHIM TÜRKMEN \\
Your medication time has come, please take your medication. \\
Thanks, I will. Ok, I will. Ok, thanks. \\
\hline Answer $\Rightarrow$ Redirect \\
\hline
\end{tabular}

Figure 16. A sample e-mail for medication reminder. 
A sample e-mail result that is set for pulse-rate alarm is displayed in Figure 17.

\begin{tabular}{l} 
It is an emergency message! Inbox $x$ \\
iBRAHIM TURKMEN <g150918023@subu.edu.tr> \\
The patient's pulse condition is critical, please take the necessary action. \\
\hline Answer $\Rightarrow$ Redirect
\end{tabular}

Figure 17. A sample pulse-rate alarm e-mail.

A sample e-mail result that is set for fire alarm is presented in Figure 18.

\section{It is an emergency message!}

\section{IBRAHIM TÜRKMEN <g150918023@subu.edu.tr>}

There is a fire, please take the necessary action.

Figure 18. A sample Fire alarm e-mail.

A sample e-mail result that is set for burglar alarm is presented in Figure 19.

It is an emergency notification me
IBRAHIM TURKMEN <g150918023@subu.edu.tr>
There is a risk of theft, please take the necessary action.
$\leftrightarrow$ Answer $\rightarrow$ Redirect

Figure 19. A sample burglar alarm e-mail.

As known, smart houses generally designed to lower the social isolation or loneliness among elder people. Besides, some studies showed that these smart houses reduced fear or anxiety (Lauriks et al., 2007).

In fact, these smart automation systems help people who tend to forget daily tasks such as taking medicines (Cahill et al. 2007).

In this present design, the automation was designed as a companion for Alzheimer patients and those who needs assistance. As well, it became a first aid system which can request first aid with emergency call and compensate security weaknesses. Besides, unlike the commercial smart house automation, this low-cost design can be affordable by more people (Fernandes et al. 2014).
In recent years Internet of Things (IoT) has considered as new technology that aims to help people in their lives. This technology is generally used SCADA based home automation studies (Niranjan et al. 2017). Due to the pandemic situation, these IoT devices become more preferable especially for Alzheimer's (Oskouei et al. 2020). Since this present study confirm and extend the previous studies, we believe this LabVIEW based study will provide new functionalities in smart automation systems especially for elderly.

As known, the quality of life can depend on not only to health but also various factors such as social companionship and entertainment (Pal \& Triyason, 2017). Even though our study was focused on limited requirements of people, this low-cost design can be improved with many different functions so that it can be preferable for many people.

\section{CONCLUSION}

In this present work, firstly, literature research was carried out for house automation system and an application was designed on LabVIEW. Therefore, the conceptual designing stages were performed. Consequently, hardware defines of the project carried out completely, required materials were analyzed, those which were suitable were chosen and the automation software was written on LabVIEW.

While the materials of the project were being determined, Alzheimer patients was prioritized and taken into consideration.

After automation carried out, most suitable materials which can establish communication was reviewed. In addition, materials which will be required if the project is actualized was determined accurately, systems in the design was completed definitely. Moreover, a program that users can make personal adjustments was set up.

In this study, it was served the purpose of facilitating of Alzheimer patients' lives. Arduino, fire extinguish system, motion sensor, pulse sensor and temperature sensor was used in the application. Communication of Arduino and sensors was successfully carried out. In the project, which was done in order that residents feel happy and safe him/herself, it was avoided to make resident lazy and tried to remove negative sides of the project.

\section{Author contributions}

Ayșe Nur Ay: Conceptualization, Investigation, WritingReviewing and Editing Barış Çokacar: Methodology, Writing-Original draft preparation, application İbrahim Türkmen: Methodology, Writing-Original draft preparation, simulation.

\section{Conflicts of interest}

The authors declare no conflicts of interest. 


\section{REFERENCES}

Aldrich F K (2003). Smart homes: past, present and future. Inside the smart home, Springer, London, 17-39.

Ay A N, Yildiz M Z \& Boru B (2017). Real-time feature extraction of ECG signals using NI LabVIEW.Sakarya University Journal of Science, 21(4), 576-583.

Bhardwaj P, Manchanda P, Chahal P, Chaudhary P \& Singh R (2017). A review paper on smart home automation. International Journal of Scientific Research and Management Studies (IJSRMS), 3, 279-283.

Cahill S, Macijauskiene J, Nygård A M, Faulkner J P \& Hagen I (2007). Technology in dementia care. Technology and Disability, 19(2-3), 55-60.

Coskun I \& Ardam H (1998). A remote controller for home and office appliances by telephone. IEEE Transactions on Consumer Electronics, 44(4), 12911297.

Douligeris C (1993). Intelligent home systems. IEEE Communications Magazine, 31(10), 52-61.

Fernández J L, Losada D P \& Domonte E P (2014). An integrated and low-cost home automation system with flexible task scheduling. In $X V$ Workshop of physical agents.

González A B, Selmes M \& Selmes J (2017). Can smart homes extend people with Alzheimer's disease stay at home? Journal of Enabling Technologies, 11(1).

Ienca M, Fabrice J, Elger B, Caon M, Scoccia Pappagallo, A, Kressig R W \& Wangmo T (2017). Intelligent assistive technology for Alzheimer's disease and other dementias: a systematic review. Journal of Alzheimer's Disease, 56(4), 1301-1340.

Koyuncu B (1995). PC remote control of appliances by using telephone lines. IEEE Transactions on Consumer Electronics, 41(1), 201-209.

Lauriks S, Reinersmann A, Van der Roest H G, Meiland F J M, Davies R J, Moelaert F, ... \& Dröes R M (2007). Review of ICT-based services for identified unmet needs in people with dementia. Ageing research reviews, 6(3), 223-246.
Maresova P, Tomsone S, Lameski P, Madureira J, Mendes A, Zdravevski E \& Rodile K (2018). Technological solutions for older people with Alzheimer's disease. Current Alzheimer Research, 15(10), 975983.

Mennicken S, Vermeulen J \& Huang E M (2014). From today's augmented houses to tomorrow's smart homes: new directions for home automation research. In Proceedings of the 2014 ACM International Joint Conference on Pervasive and Ubiquitous Computing, 105-115.

Muurling M, de Boer C, Kozak R, Religa D, Koychev I, Verheij H \& Visser P J (2021). Remote monitoring technologies in Alzheimer's disease: design of the RADAR-AD study. Alzheimer's research \& therapy, 13(1), 1-13.

Niranjan L, Nethravathi V, Bhavya Shree G, Nethravathi G, Rithu S (2017). Home Automation using SCADA \& IOT. International Journal of Engineering Research in Electronics and Communication Engineering, 4 (6).

Oskouei R J, Mousavi Lou Z, Bakhtiari Z \& Jalbani K B (2020). IoT-Based Healthcare Support System for Alzheimer's Patients. Wireless Communications and Mobile Computing.

Pal D, Triyason T \& Funikul S (2017). Smart homes and quality of life for the elderly: a systematic review. In 2017 IEEE International Symposium on Multimedia (ISM), 413-419.

Soliman M S, Alahmadi A A, Maash A A \& Elhabib M O (2017). Design and implementation of a real-time smart home automation system based on arduino microcontroller kit and labview platform. International Journal of Applied Engineering Research, 12(18), 7259-7264.

Zaro F, Tamimi A \& Barakat A (2021). Smart home automation system. International Journal of Engineering and Innovative Research, 3(1). 